\title{
RecA-Mediated Affinity Capture: A Method for Full-Length cDNA Cloning
}

BioTechniques 27:834-845 (October 1999)

Bakhyt Zhumabayeva, Alex Chenchik and Paul D. Siebert CLONTECH Laboratories, Palo Alto, CA, USA

\begin{abstract}
We describe an improved method for rapid cloning of full-length cDNA from cDNA libraries. This approach is based on the ability of Escherichia coli RecA protein to form a stable nucleoprotein complex with a linear single-stranded DNA probe and homologous sequences in circular doublestranded DNA. Hybridization of RecA-coated biotinylated DNA probes to homologous plasmid DNA creates triple-stranded complexes, which are then captured on streptavidin-coated magnetic beads. Following magnetic separation of the hybrid molecules, the enriched plasmid population is recovered by alkaline treatment, precipitat$e d$, resuspended and used to transform bacteria. Typically, many clones can then be recovered by colony hybridization screening of a single plate of the enriched library. We have used this technology to clone fulllength and alternatively spliced forms of the human bcl-xL cDNA from a human liver cDNA library.
\end{abstract}

\section{INTRODUCTION}

Obtaining a full-length cDNA can be the most challenging part of a cloning project. In recent years, polymerase chain reaction (PCR)-based genecloning strategies such as rapid amplification of cDNA ends (RACE) technology have found wide application due to the speed and relative simplicity of PCR methodology (for a review, see Reference 18). While these methods are straightforward in principle, actual execution can be difficult, especially for low-abundance transcripts, and often requires substantial optimization. Additional disadvantages of PCR-based methods include the low fidelity of thermostable polymerases and the possibility of cloning fused, internally deleted or truncated cDNAs (3). In addition, the high GC content of some cDNAs can make amplification difficult or impossible.

Screening cDNA libraries is a traditional method of cloning full-length $\mathrm{cD}$ NAs and is highly reliable, particularly when functional assays exist that permit expression cloning. This technique is preferable to PCR for cloning large, GC-rich or highly repetitive cDNA fragments, especially if high fidelity is required. However, this approach is more labor-intensive than PCR-based cDNA cloning techniques and typically requires multiple rounds of hybridiza- tion and screening. Recently, a method for library screening by PCR has been developed using bacterial cultures of a cDNA library arrayed in 96-well plates. PCR of three sets of 96-well plates can allow isolation of a desired clone. However, only a limited number of cDNA clones (roughly 500000) can be efficiently screened with this approach, so this method does not provide sufficient coverage of many libraries.

We have developed a RecA-based system for the rapid cloning of fulllength cDNAs from cDNA libraries. This approach, outlined in Figure 1, greatly reduces tedious filter hybridization and screening, while also avoiding the problems associated with PCRbased cloning. RecA's biochemical functions in recombination have been well-characterized in vitro $(1,8,9,14$, 16). RecA is required for the SOS response, DNA repair and genetic recombination in Escherichia coli. In a typical in vitro strand-exchange assay, RecA can pair single-stranded (ss)DNA and double-stranded (ds) circular DNA. The principle of using RecA to facilitate cDNA cloning from libraries has been previously described $(6-8,12,15,16)$.

However, these strategies have not been widely applied to practical problems in molecular biology. The method is based on RecA's ability to efficiently coat short single-stranded oligonucleotides or ssDNA up to several kilo- 
bases long. The resulting nucleoprotein filament has an approximate ratio of one RecA monomer to every three to four nucleotides of ssDNA $(1,9-11,17)$. In the presence of ATP, RecA-coated ssDNA can form triple-stranded hybrid structures with homologous sequences in dsDNA. These DNA hybrids, commonly referred to as displacement or D-loops, are believed to be intermediates that undergo further recombination events in vivo $(9-11,17)$. However, the strand exchange reaction can be blocked in vitro by $\gamma[\mathrm{S}] \mathrm{ATP}$, a non-hydrolyzable $\gamma$-thiol analog of ATP. The triple-stranded hybrid structures are stable when RecA is removed from Dloops formed with negatively supercoiled DNA targets $(8,17)$. By using a biotinylated, RecA-coated ssDNA as an "enrichment probe", target cDNA clones can be easily isolated from a cDNA library using streptavidin-biotin affinity interactions to isolate the resulting D-looped plasmids. The enriched plasmid population is then transformed into $E$. coli and screened by colony hybridization with a gene-specific probe.

In this paper, we describe a detailed protocol for using RecA-mediated affinity capture to expedite cloning of fulllength cDNAs. We demonstrate the utility of the method first in a carefully defined two-plasmid model system and then through rapid isolation of multiple human bcl-xL cDNAs from a human liver cDNA library constructed in pCDM8.

\section{MATERIALS AND METHODS}

\section{General Procedure}

RecA-mediated enrichment of cDNA libraries consists of three distinct steps. First, a single-stranded biotinylated enrichment probe is incubated with RecA to allow polymerization on the ssDNA. The molar amount of RecA (pmol) required for the enrichment probe is calculated by dividing the amount of DNA probe (in nanograms) by 990.

Second, the RecA-coated enrichment probe is incubated with plasmid DNA in the presence of $\gamma[\mathrm{S}]$ ATP to allow formation of triple-stranded complexes between the enrichment probe and homologous portions of the duplex DNA. Third, RecA is proteolytically removed, and the triple-helical hybrid molecules are recovered by capture on streptavidin-coated magnetic beads.

\section{RecA-Mediated Enrichment in a Model System}

The procedure detailed in the following sections was initially optimized using a model system consisting of defined mixtures of two plasmids: pAFS, which confers chloramphenicol resistance, but leaves cells ampicillin- and kanamycin-sensitive; and pBAF, which confers ampicillin and kanamycin resistance, but leaves cells chloramphenicolsensitive. $\mathrm{pBAF}$ and pAFS were mixed in the ratios shown in Table 1 , and a 262-bp fragment of pAFS was used as the enrichment probe. Following enrichment, the plasmid DNA was transformed into electrocompetent $\mathrm{DH} 5 \alpha$

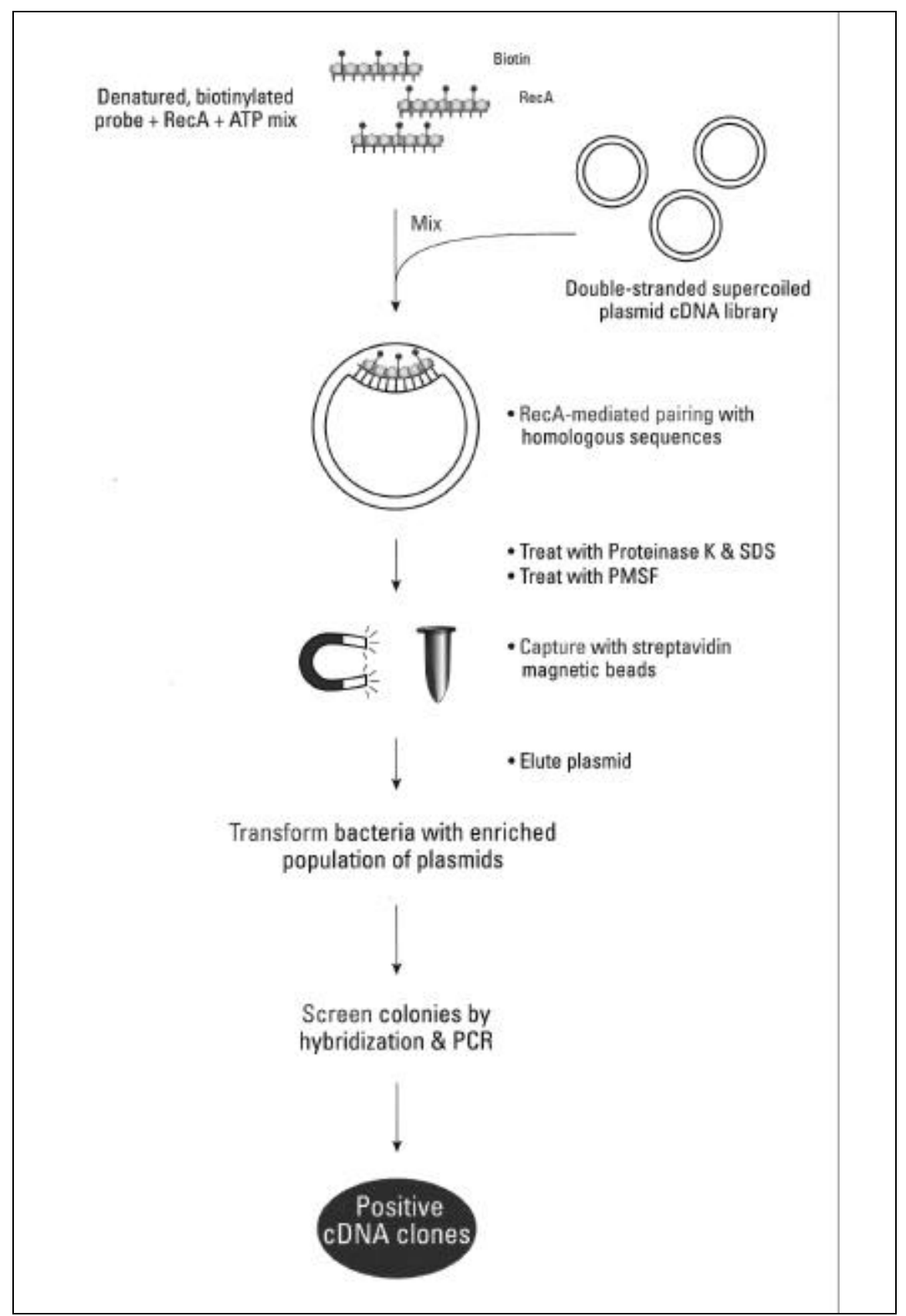

Figure 1. Schematic diagram of RecA-mediated affinity capture technology. The entire procedure, from synthesis of biotinylated probe through screening, can be performed in 2-3 days. 
cells and plated on chloramphenicol (34 $\mu \mathrm{g} / \mathrm{mL})$ and ampicillin $(50 \mu \mathrm{g} / \mathrm{mL})+$ kanamycin $(50 \mu \mathrm{g} / \mathrm{mL})$ LB plates.

\section{RecA-Mediated Enrichment of bcl- xL Clones from a cDNA Library}

Preparation of biotinylated human bcl-xL enrichment probe. A 238-bp fragment of bcl-xL cDNA (GenBank ${ }^{\circledR}$ Accession No. Z23115) was amplified from human liver Marathon-Ready ${ }^{\mathrm{TM}}$ cDNA (CLONTECH Laboratories, Palo Alto, CA, USA) according to the manufacturer's protocol, the Advantage ${ }^{\circledR}$ cDNA PCR Kit (CLONTECH Laboratories) and gene-specific PCR primers (5'-bcl-x: 5'-CAGGCGACGAGTTTGAACTGCGGTAC-3' and 3'-bcl-x: 5'AAGGCTCTAGGTGGTCATTCAGGTAAGT-3'). PCR was performed as follows: $1 \mathrm{~min}$ at $94^{\circ} \mathrm{C}$, followed by 5 cycles of $94^{\circ} \mathrm{C}$ for $30 \mathrm{~s}$ and $72^{\circ} \mathrm{C}$ for 2 min, followed by 5 cycles of $94^{\circ} \mathrm{C}$ for 30 $\mathrm{s}$ and $70^{\circ} \mathrm{C}$ for $2 \mathrm{~min}$ and 20 cycles of $94^{\circ} \mathrm{C}$ for $30 \mathrm{~s}$ and $68^{\circ} \mathrm{C}$ for $2 \mathrm{~min}$. The resulting 238-bp PCR product was visualized on 2\% Tris-acetate/EDTA (TAE) agarose gel, and a small piece (ca. 1 $\mathrm{mm}^{3}$ ) of the band was picked using a sterile Pasteur pipet and placed in a 1.5$\mathrm{mL}$ microcentrifuge tube with $200 \mu \mathrm{L}$ of deionized water and incubated at $70^{\circ} \mathrm{C}$ for 30 min with occasional vortex mixing. The identity of the PCR-amplified fragment was confirmed by sequencing.

The biotinylated probe was generated by reamplifying $2 \mu \mathrm{L}$ of the 238-bp PCR product from the previous step in a $100 \mu \mathrm{L}$ reaction mixture containing: $40 \mathrm{mM}$ Tricine- $\mathrm{KOH}\left(\mathrm{pH} 9.2\right.$ at $\left.25^{\circ} \mathrm{C}\right)$, $3.5 \mathrm{mM} \mathrm{Mg}(\mathrm{OAc})_{2}, 15 \mathrm{mM} \mathrm{KOAc}$, $3.75 \mu \mathrm{g} / \mathrm{mL}$ bovine serum albumin (BSA), $200 \mu \mathrm{M}$ of each dATP, dGTP, dCTP and dTTP, $0.2 \mu \mathrm{M}$ of $5^{\prime}$ and $3^{\prime}$ bcl-x-specific primers, $50 \mu \mathrm{M}$ biotin21-dUTP (CLONTECH Laboratories), $1 \mu \mathrm{L}$ of $\left[\alpha-{ }^{32} \mathrm{P}\right] \mathrm{dCTP}(10 \mu \mathrm{Ci}$; Amersham Pharmacia Biotech, Piscataway, NJ, USA) and $2 \mu \mathrm{L}$ of $50 \times$ Advantage KlenTaq Polymerase Mix (CLONTECH Laboratories). PCR parameters were as follows: $94^{\circ} \mathrm{C}$ for $1 \mathrm{~min}$, followed by 25 cycles of $94^{\circ} \mathrm{C}$ for $30 \mathrm{~s}$ and $68^{\circ} \mathrm{C}$ for $2 \mathrm{~min}$, followed by a final incubation at $68^{\circ} \mathrm{C}$ for $5 \mathrm{~min}$. The biotinylated PCR fragment was purified from unincorporated nucleotides and

Table 1. Enrichment of pAFS from a pAFS:pBAF Model Plasmid Library

\begin{tabular}{|lcc|}
\hline $\begin{array}{l}\text { Ratio of } \\
\text { pAFS:pBAF }\end{array}$ & $\begin{array}{c}\text { Chloramphenicol Resistance } \\
\text { Clones (\%) after Enrichment }\end{array}$ & $\begin{array}{c}\text { Enrichment factor } \\
\text { (fold) }\end{array}$ \\
\hline $1: 500$ & 98 & 490 \\
& 78 & 390 \\
$1: 5000$ & 62 & 310 \\
& 25 & 1250 \\
& 30 & 1500 \\
1:50 000 & 48 & 2400 \\
& 17 & 8500 \\
& 29 & 14500 \\
pAFS (ChIR) was mixed in different ratios (1:500, 1:5000 and 1:50 000) with pBAF & 16500 \\
(Amp ${ }^{R}$, Kan ${ }^{R}$ ) and enriched with a probe generated from pAFS. Results of three \\
independent experiments for each ratio are shown.
\end{tabular}

primers using a NucleoSpin ${ }^{\circledR}$ Extraction Kit (CLONTECH Laboratories). Biotinylation efficiency was tested by binding of $50 \mathrm{ng}$ of probe to streptavidin magnetic beads using the following procedure: $15 \mu \mathrm{L}$ of streptavidin magnetic beads $(10 \mathrm{mg} / \mathrm{mL}$; Boehringer Mannheim, Indianapolis, IN, USA) were washed $3 \times$ in $100 \mu \mathrm{L}$ of Binding buffer (10 mM Tris, $\mathrm{pH} 7.5 ; 1 \mathrm{M} \mathrm{NaCl}$ and $1 \mathrm{mM}$ EDTA) and resuspended in $30 \mu \mathrm{L}$ of Binding buffer. Next, $50 \mathrm{ng}$ (ca. $2 \mu \mathrm{L}$ ) of purified, biotinylated ${ }^{32} \mathrm{P}-$ labeled PCR fragment were added to the prewashed streptavidin magnetic beads. The tube containing magnetic beads and probe was placed in a scintillation vial and counted for total counts per minute $(\mathrm{cpm})$ and then incubated for $30 \mathrm{~min}$ at room temperature (RT) on a low-speed shaker. A magnetic stand was used to separate magnetic bead bound probe from unbound probe. The supernatant containing unbound probe was transferred to a clean $1.5-\mathrm{mL}$ tube, and the unbound fraction was counted. This biotinylated PCR product is referred to as the "enrichment probe" in the following steps.

Stable triple-helix formation. Fifty nanograms of biotinylated probe were denatured by boiling for $5 \mathrm{~min}$, immediately chilled on ice-water and centrifuged for $20 \mathrm{~s}$ at $14000 \mathrm{rpm}$ in a microcentrifuge. A pre-prepared reaction mixture containing $1 \times \operatorname{Rec} A$ buffer (25 mM TrisAc, pH 7.5, $8 \mathrm{mM}$
MgOAc, $2 \mathrm{mM} \mathrm{CoCl}_{2}, 1 \mu \mathrm{g} / \mu \mathrm{L}$ BSA), $2 \mathrm{mM} \gamma[$ S]ATP (Sigma, St. Louis, MO, USA), $1 \mathrm{mM}$ ATP (Amersham Pharmacia Biotech) and $2 \mu \mathrm{g}$ RecA (New England Biolabs, Beverly, MA, USA) was added to the denatured probe to give a final volume of $30 \mu \mathrm{L}$ and incubated at $37^{\circ} \mathrm{C}$ for $15 \mathrm{~min}$. Next, $1 \mu \mathrm{g}$ of a CsCl-purified human liver cDNA library constructed in pCDM8 (Invitrogen, Carlsbad, CA, USA) was added and mixed by pipetting. After a 20 -min incubation at $37^{\circ} \mathrm{C}, 50 \mathrm{ng}$ of $\mathrm{EcoRV}$ -

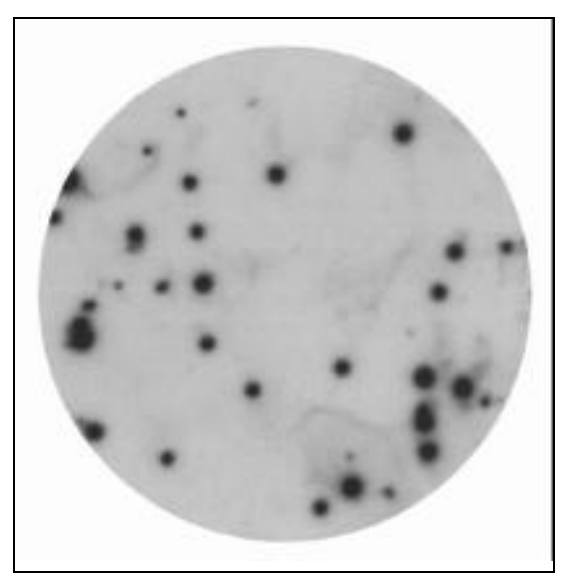

Figure 2. Colony hybridization screening of a single plate of an enriched human liver cDNA library reveals many positives. A single plate containing approximately 650 transformants from a RecA-enriched human liver cDNA library was screened by colony hybridization with a ${ }^{32} \mathrm{P}$ labeled bcl-xL probe as described in Materials and Methods and exposed to X-ray film. 
digested $\lambda$ phage DNA carrier were added to sequester excess RecA, and thereby reduce background, and then incubated for another $5 \mathrm{~min}$. Finally, RecA was removed enzymatically by adding $0.2 \mu \mathrm{g} / \mu \mathrm{L}$ proteinase $\mathrm{K}$ and $0.2 \%$ sodium dodecyl sulfate (SDS) and incubating at $37^{\circ} \mathrm{C}$ for $10 \mathrm{~min}$. Proteinase $\mathrm{K}$ was inactivated by adding up to $3 \mathrm{mM}$ phenylmethylsulfonyl fluoride (PMSF).

Capture of enriched bcl-xL cDNA clones on streptavidin-coated magnetic beads. Fifteen microliters of streptavidin beads $(10 \mathrm{mg} / \mathrm{mL})$ were washed $3 \times$ with $100 \mu \mathrm{L}$ of Binding buffer, then resuspended in $30 \mu \mathrm{L}$ of Binding buffer. Prewashed streptavidin beads were then added to the mixture containing the ssDNA-dsDNA complexes generated above and incubated for $30 \mathrm{~min}$ at RT on a shaker to keep the beads in suspension. After incubation, the supernatant was removed using a magnetic stand, and the beads were washed $3 \times$ in $1 \mathrm{~mL}$ of Washing buffer (10 mM Tris-HCl, pH 7.5, $1 \mathrm{mM}$ EDTA, $2 \mathrm{M} \mathrm{NaCl}$ ) with gentle inversion for 1-2 min. Beads were washed once more with $1 \mathrm{~mL}$ of deionized water at $37^{\circ} \mathrm{C}$ for $5 \mathrm{~min}$. After the last wash, the captured plasmids were eluted in $100 \mu \mathrm{L}$ of Elution buffer $(0.1 \mathrm{M}$ $\mathrm{NaOH}, 1$ mM EDTA) by incubating the tube for $5 \mathrm{~min}$ at RT with vortex mixing. The eluate containing the enriched plasmids was transferred to a fresh tube containing $22.5 \mu \mathrm{L}$ of Precipitation mixture $(11 \mu \mathrm{L}$ of $1 \mathrm{M}$ acetic acid, 11 $\mu \mathrm{L}$ of $3 \mathrm{M} \mathrm{NaOAc}, \mathrm{pH} 7.5$ and $10 \mu \mathrm{g}$ of glycogen). The eluate was precipitated with 2.5 volumes of $100 \%$ ethanol, mixed well and incubated for $45 \mathrm{~min}$ at $-70^{\circ} \mathrm{C}$. After incubation, the tube was centrifuged for $20 \mathrm{~min}$ at $20000 \times \mathrm{g}$. The pellet was washed with $70 \%$ ethanol, air-dried at RT and resuspended in $10 \mu \mathrm{L}$ of deionized water. Two microliters of the resuspended pellet was electroporated into electrocompetent MC1061 cells (Invitrogen). Fifty and one hundred microliters of transformed cells were plated on LB agar plates containing $40 \mu \mathrm{g} / \mathrm{mL}$ ampicillin and $10 \mu \mathrm{g} / \mathrm{mL}$ tetracycline. pCDM8 carries the supF amber supressor, which permits selection of transformed cells on ampicillin and tetracycline in appropriate host strains.

\section{Screening the Enriched Human Liver cDNA Library with the bcl-xL Probe}

Replica filters were prepared from plates containing 600-700 individual colonies of the enriched human liver cDNA library. Protran Nitrocellulose Filters (Schleicher \& Schuell, Keene, $\mathrm{NH}, \mathrm{USA}$ ) were used for colony lifting according to the manufacturer's protocol. The bcl-x probe was prepared by random priming using $[\alpha-32 \mathrm{P}] \mathrm{dCTP}$ and the DECAprime ${ }^{\mathrm{TM}}$ II DNA Labeling Kit (Ambion, Austin, TX, USA). Northern blot hybridization was performed according to the manufacturer's specifications using premade Multiple Tissue Northern (MTN ${ }^{\mathrm{TM}}$ ) Blots and ExpressHyb $^{\mathrm{TM}}$ Hybridization Solution (both from CLONTECH Laboratories).

\section{Confirmation of Positive Clones by PCR Using Gene-Specific Primers}

Positive individual clones were picked from the master plates using sterile pipet tips, placed in $100 \mu \mathrm{L}$ of LB medium containing antibiotics and grown for $1.5-2 \mathrm{~h}$ at $37^{\circ} \mathrm{C}$ on a shaker at $180 \mathrm{rpm}$. Twenty-five microliter PCRs containing $2 \mu \mathrm{L}$ of bacterial culture, $40 \mathrm{mM}$ Tricine-KOH $(\mathrm{pH} 9.2$ at $\left.25^{\circ} \mathrm{C}\right), 15 \mathrm{mM}$ KOAc, $3.5 \mathrm{mM}$ $\mathrm{Mg}(\mathrm{OAc})_{2}, 3.75 \mu \mathrm{g} / \mathrm{mL}$ BSA, $200 \mu \mathrm{M}$ of each nucleotide, $0.2 \mu \mathrm{M}$ of each primer (5'-bcl-x: 5'-CAACCCATCCTGGCACCTGGCAGAC- $3^{\prime}$ and $3^{\prime}$-bcl -x: 5'-GCTGCTGCATTGTTCCCATAGAGTTCCA-3'), and $0.5 \mu \mathrm{L}$ of Advantage Klentaq Polymerase mix were performed as follows: $94^{\circ} \mathrm{C}$ for $4 \mathrm{~min}$, 25 cycles of $94^{\circ} \mathrm{C}$ for $30 \mathrm{~s}$ and $68^{\circ} \mathrm{C}$ for $2 \mathrm{~min}$ and a final 5-min incubation at $68^{\circ} \mathrm{C}$. PCR product $(2.5 \mu \mathrm{L})$ was analyzed on $2 \%$ TAE agarose gel. Insert sizes of positive clones were determined by PCR with vector-specific primers and the same cycling parameters. Selected positive clones were sequenced from $5^{\prime}$ and $3^{\prime}$ ends using vector-specific primers, and the sequences were analyzed by basic local alignment search tool (BLAST) homology search.

\section{RESULTS}

To demonstrate the utility of RecAcoated DNA probes to enrich for ho- 
mologous sequences, we first performed enrichment on a model system composed of the kanamycin- and ampicillin-resistant plasmid pBAF spiked with low percentages of the chloramphenicol-resistant plasmid, pAFS. As an enrichment probe, we used a biotinylated PCR-amplified fragment of pAFS. Figure 1 outlines the basic procedure. Following transformation of $E$. coli with the enriched plasmid population, the efficiency of enrichment was evaluated by determining the percentage of chloramphenicol-resistant clones. As shown in Table 1, when the chloramphenicol-resistant pAFS was present at an initial level of $0.002 \%$, a single round of RecA-mediated enrichment produced more than a $10^{4}$-fold increase in pAFS representation; thus, pAFS comprised approximately $25 \%$ of the enriched population. These results suggested that RecA-coated ssDNA probes can be used to enrich for target genes in recombinant plasmid cDNA libraries.

We next used several different probes to enrich cDNA libraries and subsequently isolated cDNA clones for each. As an example, we focus in this paper on the cloning of full-length human bcl-x cDNA. A human liver cDNA library, cloned in pCDM8, was first enriched with a 238-bp biotinylated PCRamplified fragment of the bcl-x cDNA. Upon colony screening, approximately $5 \%$ of the transformed clones hybridized with a bcl-xL probe (Figure 2). Based on estimates of the original representation of bcl-xL clones in the unenriched library, this corresponds to an 800 -fold enrichment. The representation of bcl-x in the original library was estimated using PCR to compare the frequency of bcl-xL clones with $\beta$-actin and glyceraldehyde 3-phosphate dehydrogenase (GAPDH), which were assumed to be $0.1 \%-0.2 \%$ of the total population, based on previously published data (5). Seventeen positive clones were selected for further analysis and tested by PCR using gene-specific primers (Figure 3, upper panel). The insert size of each clone was also determined by PCR using vector-specific primers (Figure 3, lower panel), and all 17 clones were sequenced from the $5^{\prime}$ and $3^{\prime}$ ends. Clones B7 and B9 proved to be false positives; however,
BLAST homology searches of the remaining 15 clones showed 99\% identity to the human bcl-xL cDNA sequence (GenBank ${ }^{\circledR}$ Accession No. Z23115). These results confirm the sequence specificity of RecA-mediated D-loop formation and its utility in library enrichment. The insert sizes of all 15 clones were between 1.4 and $2.8 \mathrm{~kb}$ and were thus significantly longer than the GenBank sequence. We selected three clones of differing sizes for full-length sequence analysis and comparison to the known bcl-x cDNA and genomic (GenBank Accession No. D30746) sequences (Figure 5). We next performed northern blot analysis with the human bcl-x probe (Figure 4). Our results show that bcl-xL mRNA is expressed as a single, $2.7-\mathrm{kb}$ mRNA in multiple human tissues including heart, brain, placenta, lung, liver, skeletal muscle, kidney and pancreas; the size is similar to the bcl-x transcript in chicken. Figure 3 shows that six clones (B1, B4, B10, B12, B14 and B16) have inserts approximately $2.7 \mathrm{~kb}$ in length and are thus candidates for the full-length bcl-x clones. Another five clones (B2, B3, B5, B6 and B15) range between 2.4 and $2.6 \mathrm{~kb}$. Only two clones, B13 and $\mathrm{B} 17$, are less than $2 \mathrm{~kb}$.

There are two alternatively spliced forms of bcl-x: bcl-xL and bcl-xS (2,4, 13). bcl-xS is the smaller of the two mRNAs and lacks the sequences corresponding to amino acids $127-189$ of $\mathrm{bcl}-\mathrm{xL}$. To determine which form is expressed in human liver, we sequenced three clones (B16, $2.7 \mathrm{~kb}$; B3, $2.4 \mathrm{~kb}$ and the shortest clone $\mathrm{B} 17,1.5 \mathrm{~kb}$ ) using a sense-strand primer designed for 412-437 positions of bcl-xL mRNA. Sequencing confirmed that these clones correspond to bcl-xL cDNAs.

A homology search of the $5^{\prime}$ untranslated regions (UTRs) of B3, B16 and $\mathrm{B} 17$ revealed $96 \%$ homology to bp 370-607 of the human bcl-x genomic sequence (GenBank Accession No. D30746); however, bp 608-895 of the genomic sequence has been spliced out in all three of these clones (Figure 5). Interestingly, this putative intron was present in clone B14 (data not shown). The unspliced B14 clone could be de-

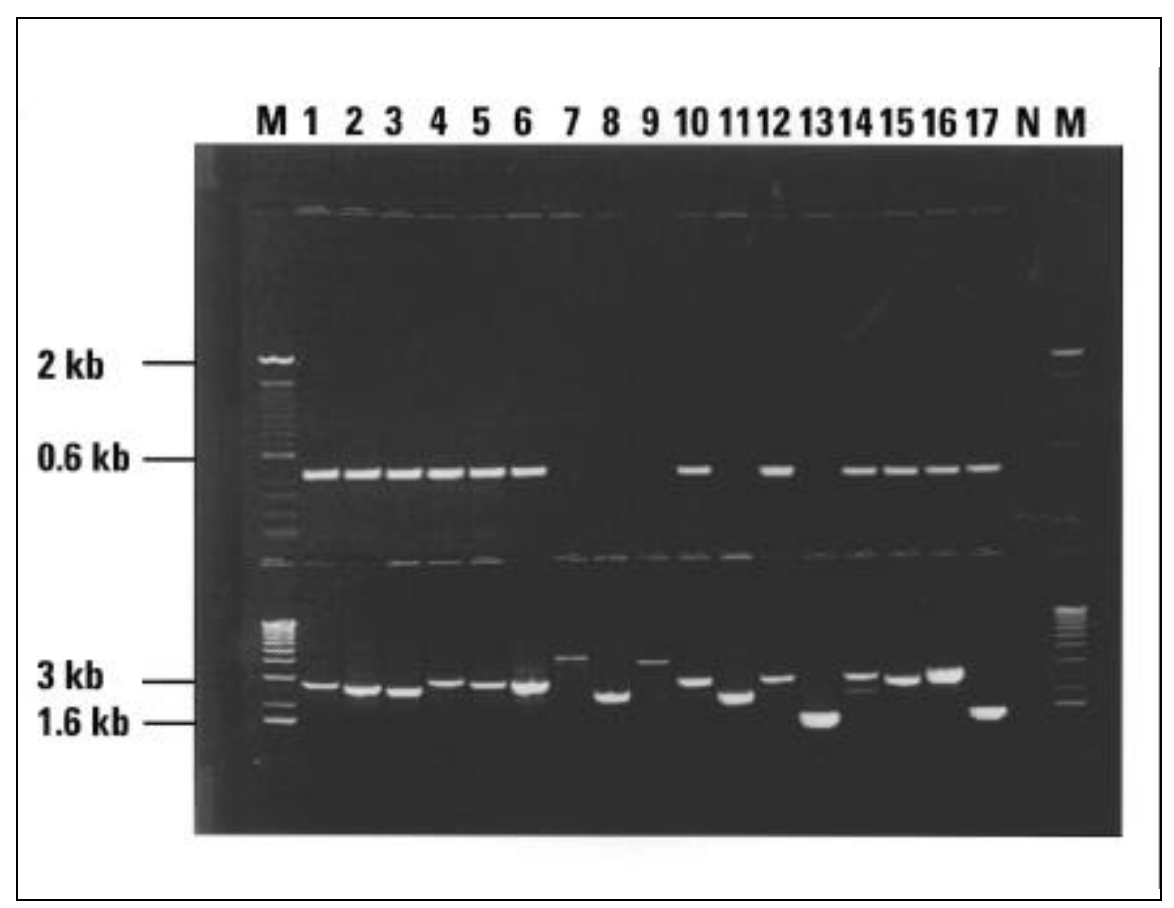

Figure 3. PCR confirmation of 17 putative bcl-xL clones identified by colony screening. bcl-xL clones were positively identified by PCR with gene-specific primers (upper panel). The sizes of the inserts were determined using vector-specific primers (lower panel). M, DNA size markers; N, negative control. Lanes 7 and 9 were false positives. Lanes 8,11 and 13 were true positives; however, these cDNAs lacked the binding site for one of the gene-specific primers and thus gave no PCR product in the upper panel. For more information, see Materials and Methods. 
rived from a precursor mRNA. Based on the sequence analysis, clone B16, which has a 306-bp 5' UTR, appears to be the best candidate for a full-length bcl-xL mRNA. Because the genomic sequence available in GenBank is incomplete, our results do not permit us to deduce the complete intron-exon structure of the human bcl-x gene.

\section{DISCUSSION}

We have demonstrated that enriching a plasmid library with RecA-mediated affinity capture technology can significantly reduce the number of clones that must be screened to obtain a full-length cDNA. In the case of the human bcl-x gene, we obtained many specific clones within 2-3 days by screening a single $90-\mathrm{mm}$ plate, thus dramatically shortening the process of library screening. Several factors affect the efficiency of a RecA-mediated search for homologous DNA sequences. One is the requirement for the nucleoside triphosphate cofactor ATP. RecA is a DNA-dependent ATPase, and ATP is hydrolyzed by RecA throughout each nucleoprotein filament. RecA promoted dissociation of ATP directly affects the stability of the deproteinized triple-helix complexes in vitro. Our procedure uses a non-hydrolyzable analog of ATP, $\gamma[\mathrm{S}] \mathrm{ATP}$, to block disassembly of triple-helix complex. We have tested the effects of different ratios of $\gamma[\mathrm{S}] \mathrm{ATP}$ and ATP, as well as $\gamma[\mathrm{S}] \mathrm{ATP}$ alone, on the recovery of enriched clones (data not shown). When used alone, $\gamma[\mathrm{S}] \mathrm{ATP}$ gave a much higher background and a correspondingly reduced enrichment. A 1:2 ratio of ATP: $\gamma[\mathrm{S}] \mathrm{ATP}$ gave the highest recovery of homologous clones with low levels of nonspecific background.

The second important criterion for successful enrichment is the quality and integrity of the dsDNA used as the target. To minimize the level of non-specific binding and maximize the stability of the triple-helix complex after removal of RecA, the plasmid library should be purified through a $\mathrm{CsCl}$ gradient. When compared to alkalinebased commercial plasmid isolation kits, enrichment efficiency was more than 10-fold higher using $\mathrm{CsCl}$-purified
DNA. However, some commercial plasmid isolation kits allow isolation of higher quality super-helical DNA with only minor modifications to the protocol. In particular, DNA purified with the NucleoBond $^{\circledR}$ Plasmid Isolation Kit (Macherey-Nagel GmbH, Duren, Germany) gave comparable results to $\mathrm{CsCl}$ purified DNA (data not shown).

The ratio of biotinylated probe to RecA protein is also important. Given that one RecA monomer binds to three nucleotide bases on ssDNA $(1,8,9)$, we calculated that 51 pmol of RecA protein should be used for every $50 \mathrm{ng}$ of biotinylated probe (51 pmol is approximately equal to $2 \mu \mathrm{g}$ of RecA protein). Before adding RecA, the concentration of biotinylated probe should always be confirmed by spectrophotometer or fluorometer to ensure an optimal ratio.

The quality of the biotinylated PCR probe is another important factor. We have found that $50 \%-75 \%$ binding of biotinylated PCR product to the streptavidin magnetic beads in control experiments allows successful enrichment of desired cDNA clones. We tested several sources of biotin-dUTP and found that biotin-21-dUTP gave the best enrichment (results not shown). This may be due to the longer [21 nucleotide (nt)] spacer arm used in this analog. The optimal size of the biotinylated probe was 200-600 bp, although we obtained comparable efficiency with probes as

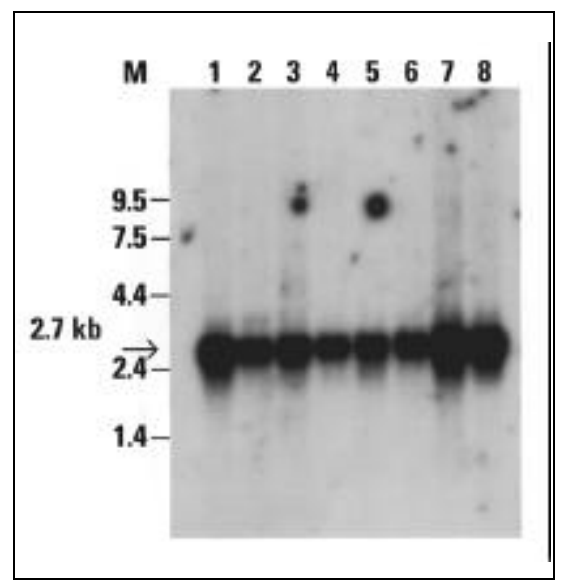

Figure 4. Northern blot reveals expression pattern of human bcl-xL gene. A human MTN blot was probed with a ${ }^{32} \mathrm{P}-$-labeled bcl-xL probe as described in Materials and Methods. Lanes 1-8: heart, brain, placenta, lung, liver, skeletal muscle, kidney and pancreas. M: mRNA size marker. The bcl-xL mRNA size corresponds to $2.7 \mathrm{~kb}$. 
small as $100 \mathrm{bp}$. However, biotinylated 28- and 48-mers did not give efficient enrichment and generated high nonspecific background.

Background is caused by the collective effects of the biotinylated probe, RecA and also nonspecific binding of streptavidin magnetic beads. Most background comes from nonspecific binding of streptavidin-coated magnetic beads. Background may also occur if an enrichment probe has some sequence similarity to some repetitive elements, poly(A) sequences or sequences shared with other genes. We have also noticed that a higher nonspecific background is directly correlated to greater complexity of the cDNA library.

Our experiments with gel-shifting assays showed that up to $30 \%$ of the triple-helix complex could form the concatamers (data not shown). The concatamers could be one source of nonspecific background that cannot be eliminated by washing. Adding an equal amount of EcoRV-digested $\lambda$ phage DNA as the enrichment probe after D-loop formation significantly decreases a concatamer formation by binding the free RecA in a model experiment. Increasing the amount of carrier DNA did not have any more effect. There are two alternatively spliced forms of human bcl-x: bcl-xL and bcl-
$\mathrm{xS}$. Both forms encode functional proteins $(2,4,13)$. bcl-xS is the smaller of the two mRNAs, and lacks the sequences corresponding to amino acids 127189 of bcl-xL. The two forms appear to have identical 5' and 3' untranslated sequences. Human bcl-xS was cloned first from a thymic cDNA library using an $0.8-\mathrm{kb}$ fragment of chicken bcl-x cDNA as a probe. Human bcl-xL was later cloned by PCR using primers derived from the $5^{\prime}$ and $3^{\prime}$ UTRs of bcl-xS. Both forms are expressed in many human tissues (References 2 and 4) (Figure 4).

Clone B16 represents the longest human bcl-xL cDNA described to date. Our analysis of this putative full-length bcl-x clone has allowed us to determine the $5^{\prime}$ UTR sequence and define the position of a 287-bp intron in the bcl-x gene. Interestingly, sequence comparisons of the $3^{\prime}$ ends of our bcl-xL clones revealed only partial homology to exon III of the rat (GenBank Accession No. X82537) and mouse bcl-x genes (GenBank Accession No. U18289) (data not shown).

In conclusion, the cloning of numerous full-length or near full-length bcl$\mathrm{xL}$ cDNAs from a single plate of an enriched library demonstrates that RecA-mediated affinity capture technology is a rapid and efficient method for screening cDNA libraries. The

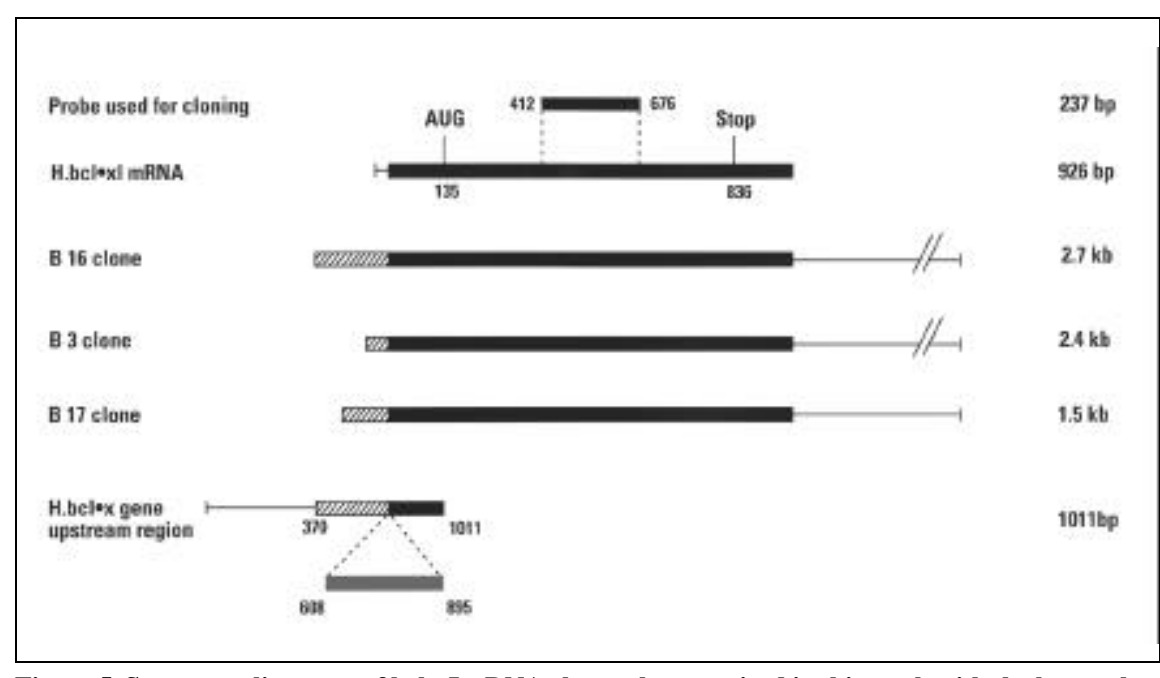

Figure 5. Sequence alignment of bcl-xL cDNA clones characterized in this work with the known human bcl-xL mRNA (GenBank No. Z23115) and genomic (GenBank No. D30746) sequences. Crosshatching shows additional $5^{\prime}$ UTR sequence found in several of our cDNAs that is homologous to positions 370-607 of the human bcl-x gene. Solid black lines indicate previously known bcl-xL mRNA sequence. The three new cDNA clones lack sequence corresponding to positions 608-895 region of the human genomic bcl-x sequence (solid gray). Non-homologous portions of all clones are shown by a single line. prevalence of larger inserts $(35 \%$ were nearly the size of mRNA) suggests that the method may also enrich for fulllength clones. This method allows screening of $1-5 \times 10^{9}$ clones $(1 \mu \mathrm{g}$ of a typical plasmid library) in 2-3 days. Screening this many clones by conventional methods would have taken $2-3$ weeks and been much more labor-intensive. Finding an unspliced form of bcl-xL cDNA clone (B14) suggests that this method could also be used for cloning alternatively spliced gene products. This technique also provides an alternative approach to RACE technology that eliminates the fidelity problems associated with PCR and may be more suitable for low abundance genes.

A second round of enrichment could be helpful for extremely low abundance genes. However, the enriched plasmid population cannot be used directly for the second enrichment round because (i) the 2-20 ng of plasmid DNA recovered at the final stage is insufficient for the second round, and (ii) the supercoiled structure of plasmid DNA may be damaged. This structure is necessary for the stability of the triple-helix. A second round of enrichment could be performed if the entire enriched plasmid DNA was transformed into $E$. coli and grown in LB medium or on LB agar plates. Furthermore, the isolated plasmid DNA could be used for the second round of enrichment. However, our results indicate a successful enrichment may occur by increasing the amount of enrichment probe and the cDNA library up to $5 \mu \mathrm{g}$. The simplicity of this method allows processing of multiple samples in parallel and makes library screening a more straightforward, routine procedure. The technology is also well-suited for isolating fulllength clones using partial sequence cDNA fragments obtained by cDNA subtraction or differential display.

\section{ACKNOWLEDGMENTS}

We thank Drs. Stephen Kowalczykowski and Eugene Zaitsev of the University of California at Davis for their helpful advice and suggestions. We thank Valerie Natale and David Gunn of CLONTECH for critical editing of the manuscript. 


\section{REFERENCES}

1.Bianco, P.R. and G.M. Weinstock. 1996. Interaction of the RecA protein of Escherichia coli with single-stranded oligodeoxyribonucleotides. Nucleic Acids Res. 24:4933-4939.

2.Boise, L.H., M. Gonzales-Garcia, C.E. Postema, L. Ding, T. Lindsten, L.A.Turka, X. Mao, G. Nunez and C.B. Thompsom. 1993. Bcl-x, a bcl-2-related gene that functions as a dominant regulator of apoptotic cell death. Cell 74:597-608.

3.Chenchik, A., L. Diachenko, F. Moqadam, V. Tarabykin, S. Lukyanov and P.D. Siebert. 1996. Full-length cDNA cloning and determination of mRNA 5' and 3' ends by amplification of adaptor-ligated cDNA. BioTechniques 21:526-534.

4.Dole, M.G., M.F. Clarke, P. Holman, M. Benedict, J. Lu, R. Jasty, P. Eipers, C.B. Thompson et al. 1996. Bcl-xS enhances adenoviral vector-induced apoptosis in neuroblastoma cells. Cancer Res. 56:5734-5740.

5.Hagen, F.S., C.L. Gray and J.L. Kuijper. 1988. Assaying the quality of cDNA libraries. BioTechniques 6:340-345.

6.Hakvoort, T.B.M., J.A.A. Spijkers, J.L.M. Vermeulen and W.H. Lamers. 1996. Preparation of a differentially expressed, full-length cDNA expression library by RecA-mediated triple-strand formation with subtractively enriched cDNA fragments. Nucleic Acids Res. 24:3478-3480.

7.Hakvoort, T.B.M., J.L.M.Vermeulen and W.H. Lamers. 1998. Enriched full-length cDNA expression library by RecA-mediated affinity capture, p. 259-269. In P.D. Siebert and J.W. Larrick (Eds.), Gene Cloning and Analysis by RT-PCR. Eaton Publishing, Natick, MA.

8.Honigberg, S.M., B.J. Rao and C.M. Radding. 1986. Ability of RecA protein to promote a search for rare sequences in duplex DNA. Proc. Natl. Acad. Sci. USA 83:95869590.

9.Hsieh, P., C.S. Camerini-Otero and R.D. Camerini-Otero. 1992. The synapsis event in the homologous pairing of DNAs: RecA recognizes and pairs less than one helical repeat of DNA. Proc. Natl. Acad. Sci. USA 89:64926496.

10.Kowalczykowski, S.C. and A.K. Eggleston. 1994. Homologous pairing and DNA strandexchange proteins. Annu. Rev. Biochem. 63:991-1043.

11.Rao, B.J., M. Dutreix and C.M. Radding. 1991. Stable three-stranded DNA made by RecA protein. Proc. Natl. Acad. Sci. USA 88:2984-2988.

12.Rigas, B., A.A. Welcher, D.C. Ward and S.M. Weissman. 1986. Rapid plasmid library screening using RecA-coated biotinylated probes. Proc. Natl. Acad. Sci. USA 83:95919595.

13.Schott, A.F., I.J. Apel, G. Nunez and M.F. Clarke. 1995. Bcl-xL protects cancer cells from p53-mediated apoptosis. Oncogene 11:1389-1394.

14.Sena, E.P. and D.A. Zarling. 1993. Targeting in linear DNA duplexes with two complementary probe strands for hybrid stability. Nat. Genet. 3:365-372.
15.Taidi-Laskowski, B., D. Tyan, S.M. Honigberg, C.R. Radding and F.C. Grumet. 1988 Use of RecA protein to enrich for homologous genes in genomic library. Nucleic Acids Res. 16:8157-8169.

16.Teintze, M., I.I. Arzimanoglou, C.I.P. Lovelace, Z. Xu and B. Rigas. 1995. RecA-assisted rapid enrichment of specific clones from model DNA libraries. Biochem. Biophys. Res. Comm. 211:804-811.

17.Tracy, R.B. and S.C. Kowalczykowski. 1996. In vitro selection of preferred DNA pairing sequences by the Escherichia coli RecA protein. Genes Dev. 10:1890-1903.

18.Zhang, Y. and M.A. Frohman. 1997. Using rapid amplification of cDNA ends (RACE) to obtain full-length cDNAs, p. 61-87. In I.G. Cowel and C.A. Austin (Eds.), cDNA Library Protocols. Humana Press, Totowa, NJ.

Received 27 April 1999; accepted 6 July 1999.

\section{Address correspondence to:}

Bakhyt Zhumabayeva

CLONTECH Laboratories

1020 E. Meadow Circle

Palo Alto, CA 94303, USA

Internet: bdzhumabayeva@clontech.com 